\title{
Six Phase to Ground Fault Detection and Classification of Transmission Line using ANN
}

\author{
Ebha Koley \\ Department of Electrical \\ Engineering \\ National Institute of Technology \\ Raipur, 492010, C.G., India
}

\author{
Anamika Yadav \\ Department of Electrical \\ Engineering \\ National Institute of Technology \\ Raipur, 492010, C.G., India
}

\author{
A. S. Thoke \\ Department of Electrical \\ Engineering \\ National Institute of Technology \\ Raipur, 492010, C.G., India
}

\begin{abstract}
The six phase transmission line has received considerable attention in recent times as an alternative to the three phase transmission, since it possess several advantages over three phase transmission line. Six-phase transmission line can provide same power transfer capability as three phase on a smaller right-of- way, for the same electric field and audible noise criteria, with smaller structures and reduced overall cost. A total of 120 faults can occur in six phase transmission line. The design of adequate protective scheme is essential for the protection of six phase transmission line. This paper reports the application of Artificial Neural Network for protection of six phase transmission line against six phase to ground faults, which has not been reported yet to the best of the knowledge of the authors. Effects of variations in the fault inception angle $\left(\Phi_{\mathrm{i}}\right)$, fault resistance $\left(\mathrm{R}_{\mathrm{f}}\right)$, distance to fault $\left(\mathrm{L}_{\mathrm{f}}\right)$ have been studied broadly on the performance of the neural network based protection scheme for six phase to ground fault type. Six phase transmission line is modeled using the Simulink $\AA$ and Simpowersystem ${ }^{\circledR}$ toolboxes of MATLAB ${ }^{\circledR} 7.01$. The algorithm employs the fundamental components of voltage and current signals. The results indicate the suitability of proposed technique and its adaptability to changing system conditions. The simulation results of ANN based fault detector and classifier indicate that algorithm correctly detects and classifies the six phase to ground fault.
\end{abstract}

\section{Keywords}

Six Phase Transmission Line, ANN, Transmission Line Protection.

\section{INTRODUCTION}

The growing demand of electrical power has resulted in an increase in the power transfer capability. To meet this ever increasing demand the most common solution of increasing the power transfer capability is to increase the transmission voltage. EHV transmission lines are used for this purpose. EHV transmission line has the drawback of introducing strong electric fields at the ground surface, with possible biological effects, visual pollution, audible noise, and right of way [1]. The other alternative to increase the power transmission capability is HVDC transmission. However, a major drawback of HVDC transmission is the huge capital required for installation and operation. Barnes and Barthold proposed the use of multi-phase (higher than three-phase) power transmission system [2]. Six phase transmission line is one of the most promising alternatives among the multi-phase transmission systems. It has several advantages over threephase transmission systems. Six-phase transmission line can provide same power transfer capability as three phase on a smaller right-of- way with smaller structures and reduce overall cost [3]. Six-phase transmission line has lower radio noise and audible noise performance than three phase transmission line [4]. The concept of six-phase has been described in the literature in several papers [1-7]. The capacitance switching phenomenon in six phase transmission line has been studied and compared with three phase transmission line in [5]. Six phase transmission system can use capacitor banks to improve power factor, voltage regulation and power handling capability. Apart from these advantages six phase transmission line has reduced reactive power losses, increased power at receiving end, reduced reactive power requirement for maintaining stable load voltage, reduced rating of compensating devices.

The fault analysis and design of an adequate protection scheme are the two most important aspects. The number of occurrence of possible fault combinations in six phase transmission line are more as compared to three phase transmission line. Out of 120 types of possible fault combinations, 23 are significant faults in six phase transmission line whereas, out of 11 types of fault combinations, 5 significant faults can occur in three phase double circuit transmission line. So the complexity of protection scheme for six - phase transmission line is more as compared to three phase transmission.

Various faults likely to occur on six phase system and protection schemes against these faults have been analyzed in several papers [6-8]. The fault analysis for SpringdaleMcCalmont line operating as a $138-\mathrm{kV}$ six-phase line is presented in [6]. The complications encountered when using distance relays to protect six phase transmission lines is analyzed by Redfern in [7]. In this paper, various short circuit fault conditions have been analyzed by a full scheme sixphase distance relay.

This paper reports the application of artificial neural network based fault detector and classifier against six phaseto-ground faults. In recent years, artificial neural network (ANN) has emerged as a powerful tool for different power system applications because of its pattern recognition, generalization and learning ability [8].

\section{POWER SYSTEM NETWORK SIMULATION}

A $138 \mathrm{kV}, 60 \mathrm{~Hz}$ Six phase transmission line is modeled using the Simulink ${ }^{\circledR}$ and Simpowersystem ${ }^{\circledR}$ toolboxes of MATLAB7.01. The six phase transmission line is modeled using the distributed parameter model. At the far end two 
three phase loads of 250MW and 100MVAr are connected. The short circuit capacity of each source is 1.25 GVA and $\mathrm{X} / \mathrm{R}$ is 10 . Various types of faults and different system conditions are simulated. The algorithm employs the fundamental components of voltage and current signals. The single line diagram of the system under study is shown in Fig.1.

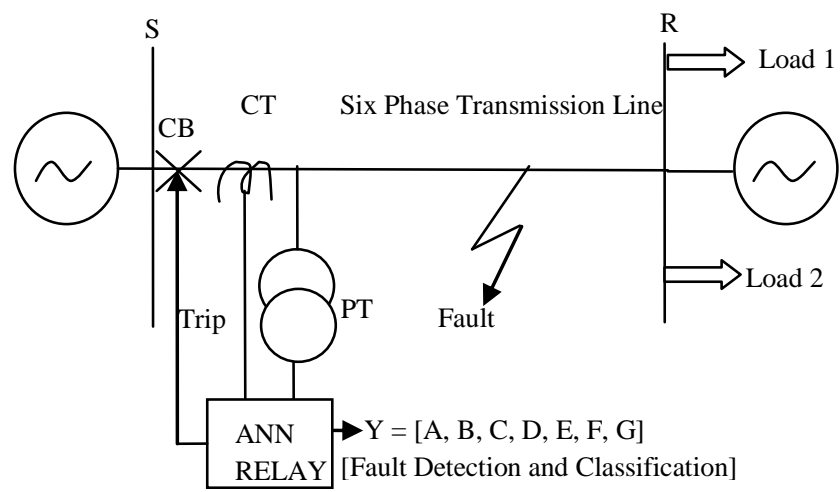

Fig.1. Six Phase Transmission Line Power System under Study

\section{DESIGN PROCESS OF ANN BASED FAULT DETECTOR AND CLASSIFIER}

\subsection{Patterns Generation and Preprocessing}

To reduce the size of neural network and improve the performance of signals preprocessing is a useful method. It increases the speed of training of neural network. Fig. 2 shows the steps involved in pre-processing of the fault patterns (signals). After simulating the six phase transmission line model in Matlab software, the fundamental component of current samples are extracted at the relay location (end S). Further, the signals are processed by simple 2nd-order lowpass Butter worth filter. The filter has a cut-off frequency of $480 \mathrm{~Hz}$. Current signals are sampled at $1.2 \mathrm{kHz}$ (20 samples per $60 \mathrm{~Hz}$ cycle). This sampling rate is chosen here because it is compatible with the sampling rates commonly used in digital relays. The Discrete Fourier Transform (DFT) block of MATLAB ${ }^{\circledR}$ SimPowerSystem toolbox was utilized to obtain the magnitudes of the signals just after the fault occurrence and only the fundamental frequency components were used. In this manner, the inputs for neural network i.e. the fundamental component of current samples were obtained from simulation. These input signals are used to train the proposed neural network.

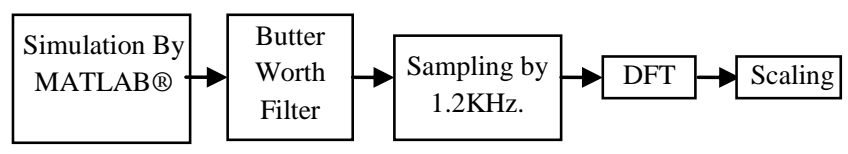

Fig.2 Pre-processing of the fault patterns

The design process of the ANN based fault classifier have the following steps:

a) Preparation of a suitable training data set comprising of all possible cases that the ANN needs to learn.

b) Selection of a suitable ANN structure for a given application.

c) Training of ANN. d) Testing of the trained ANN using test patterns to check its generalization accuracy.

The training data set of an ANN contains the essential information to map the input patterns to corresponding output patterns. Six phase to ground fault with different fault conditions were considered and training patterns were generated with varying power system network conditions. Fault location, fault resistance and fault inception angle were changed to obtain training patterns covering a wide range of different power system conditions as shown in Table I. The total number of samples generated for training is 1 (fault type) $* 8$ (distance in $\mathrm{km}$ from the source end to fault) $* 2$ (fault resistance) $* 2$ (fault inception angle) $=32,10$ post fault samples have been extracted from each fault scenario. In addition to this some samples of no fault situation has been also added to discriminate between no fault and faulty situation. The total fault samples used in training are 370 . The simulated training data set were used to train the ANN-based fault detector and classifier.

Table 1. Training patterns data generation

\begin{tabular}{|c|c|c|}
\hline $\begin{array}{c}\text { Sl. } \\
\text { No. }\end{array}$ & Parameter & Set value \\
\hline 1. & Fault type & ABCDEFG \\
\hline 2. & Fault location $\mathrm{L}_{\mathrm{f}}(\mathrm{km})$ & $5,10,20,30,40,50,60,65 \mathrm{~km}$ \\
\hline 3. & Fault inception angle & 0 \& $90 \mathrm{deg}$ \\
\hline 4. & Fault resistance & 0 and $100 \Omega$ \\
\hline
\end{tabular}

\subsection{Input and output selection}

The fundamental components of current samples of six phases are used as input to the ANN based fault detector and classifier. To generate the input matrix; 10 no. of post fault samples have been extracted from each fault scenario. The ANN based fault detector and classifier has to detect as well as to classify the fault so the output matrix should involve the all the phases of six phase transmission line and ground. The outputs of ANN are 1 or 0 for detection of faults and type of fault. If the phase is faulty, the output is 1 otherwise it is 0 . Thus, the input and output of ANN are as shown in the following equations (1) and (2).
$\mathrm{X}=\left[\mathrm{I}_{\mathrm{A}}, \mathrm{I}_{\mathrm{B}}, \mathrm{I}_{\mathrm{C}}, \mathrm{I}_{\mathrm{D}}, \mathrm{I}_{\mathrm{E}}, \mathrm{I}_{\mathrm{F}}\right]$
$\mathrm{Y}=[\mathrm{A}, \mathrm{B}, \mathrm{C}, \mathrm{D}, \mathrm{E}, \mathrm{F}, \mathrm{G}]$

$\mathrm{X}$ represents the input matrix and $\mathrm{Y}$ represents the output matrix.

\subsection{Structure of ANN based fault detector and classifier}

The ANN based fault detector and classifier has three layers. The number of neurons in the input layer is 6 since the current samples of six phases are used as input to the neural network. The output layer has seven neurons as the ANN based fault locator has to classify the faults. The number of neurons in the hidden layer is based on series of trials. It is found that the 3 neurons in the hidden layer lead to the best performance. Activation functions used are hyperbolic tangent sigmoid function. The architecture of ANN based fault detector and classifier for six phase faults is shown in Fig. 3. 


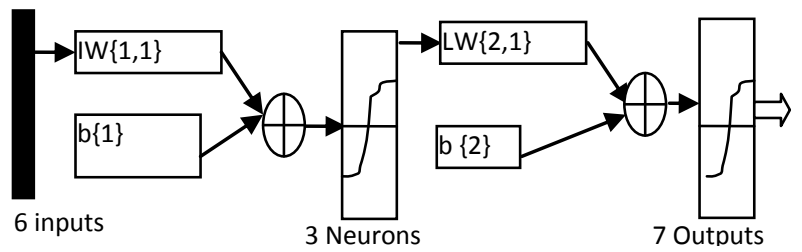

Fig. 3 Architecture of ANN Based Fault detector and classifier

\subsection{Training of NN}

The network considered was trained with LevenbergMarquardt (Trainlm) training algorithm. It has been found that ANN fault classifier with 6 inputs, 3 neurons in hidden layer and 7 neuron in output layer (6-3-7) is capable of minimizing the mean square error (mse) to a final value of 1e-04 as shown in Fig. 4.

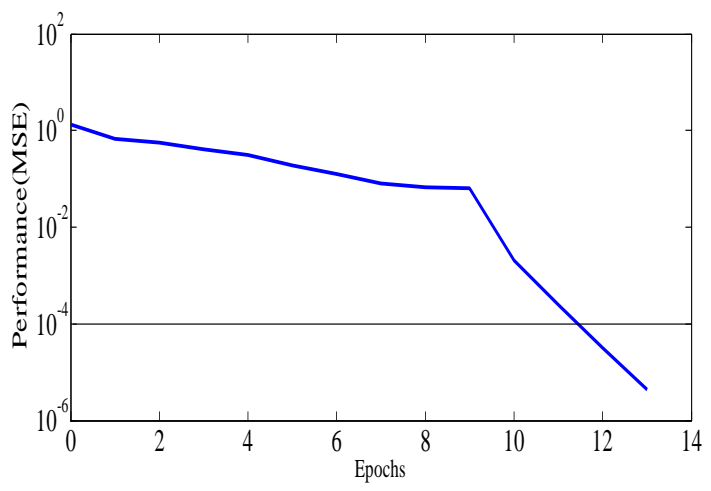

Fig. 4 Training figure obtained with LevenbergMarquardt algorithm.

\section{Test Results}

After training the artificial neural network has been tested to check its accuracy. The network is extensively tested using independent data sets consisting of fault scenarios never used previously in training. For different faults of the validation/test data set, fault type, fault location and fault inception time were changed to investigate the effects of these factors on the performance of the proposed ANN based fault detector and classifier. Extreme cases like faults near the source ends, fault resistance, fault inception times were also included in the validation data set. For example, a close in six phase fault "ABCDEFG" is applied at $1 \mathrm{~km}$ from the sending end bus "S" in the power system network with $100 \Omega$ fault resistance, fault inception time $=0.0402 \mathrm{~ms}(150 \mathrm{deg}$. fault inception angle). After the occurrence of fault the currents in respective phases will change. The waveform of six phase currents in this fault situation is shown in Fig. 4. From the figure it can be seen that fault has occurred at $0.0408 \mathrm{sec}$ and current waveform has changed at sample no. 49 (Fault inception time $=49 \times 0.000833$ sampling time $=0.0408 \mathrm{sec}$ ). The ANN based fault detector and classifier exploit these changes.

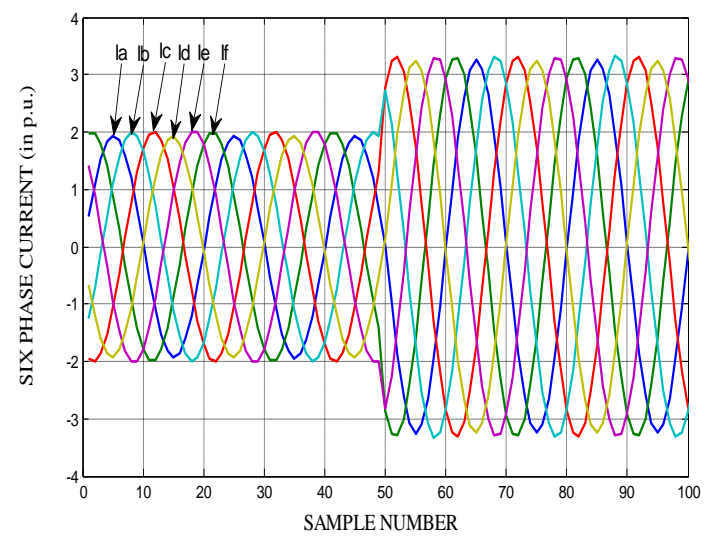

Fig.5 Waveform of six phase currents at $1 \mathrm{~km}, 100 \Omega$ and $150^{\circ}$ inception angle, Fault inception time 0.0408 sec.

The test result of ANN based fault detector for this particular case is shown in Fig 6, which shows the seven outputs of ANN based fault detector/classifier and six phase currents plotted against sample number. $\mathrm{X}$-axis represents number of samples and Y-axis represents the phases. It is clear that during normal condition all seven outputs of ANN are low (zero) and just after occurrence of fault, the outputs of respective phases (ABCDEF) and ground $(\mathrm{G})$ becomes high (one) and remains constantly high for further cycles. It can be seen from the Fig. 6 that ANN based fault detector and classifier takes 10 samples $(0.0083 \mathrm{sec}$.) to detect and classify the fault.

The time of operation of ANN based fault detector and classifier can be calculated as follows:

Fault occurred at sample no. 49

Fault inception time $=49 \times 0.000833$ (sampling time in sec.) $=0.0408 \mathrm{sec}$.

Fault detected at sample no. 59

Fault detected at time $=59 \times 0.000833$ (sampling time in sec.)

$=0.0491 \mathrm{sec}$

Time of operation $=$ Fault detection time -

Fault inception time

$=0.0491-0.0408$

$=0.0083 \mathrm{sec}$.

The system frequency is $60 \mathrm{~Hz}$. To complete one cycle, time required is $0.0167 \mathrm{sec}$. From the calculation it is clear that the time taken by ANN based fault detector is $0.0083 \mathrm{sec}$.(i.e. less than one cycle of fundamental current waveform). Thus, ANN based Fault detector and classifier is able to detect and classify the fault within one cycle after the inception of fault.

The testing data set has been created considering different fault scenarios and the test results of ANN based Classifier and Detector are given in Table II. For healthy condition (no fault condition) the output of ANN based fault detector and classifier should be zero and for faulty condition it should be one in the corresponding faulty phases. From the Table II it is clear that after the occurrence of fault the output of $\mathrm{NN}$ in the corresponding phases go high (Aprrox. one). 

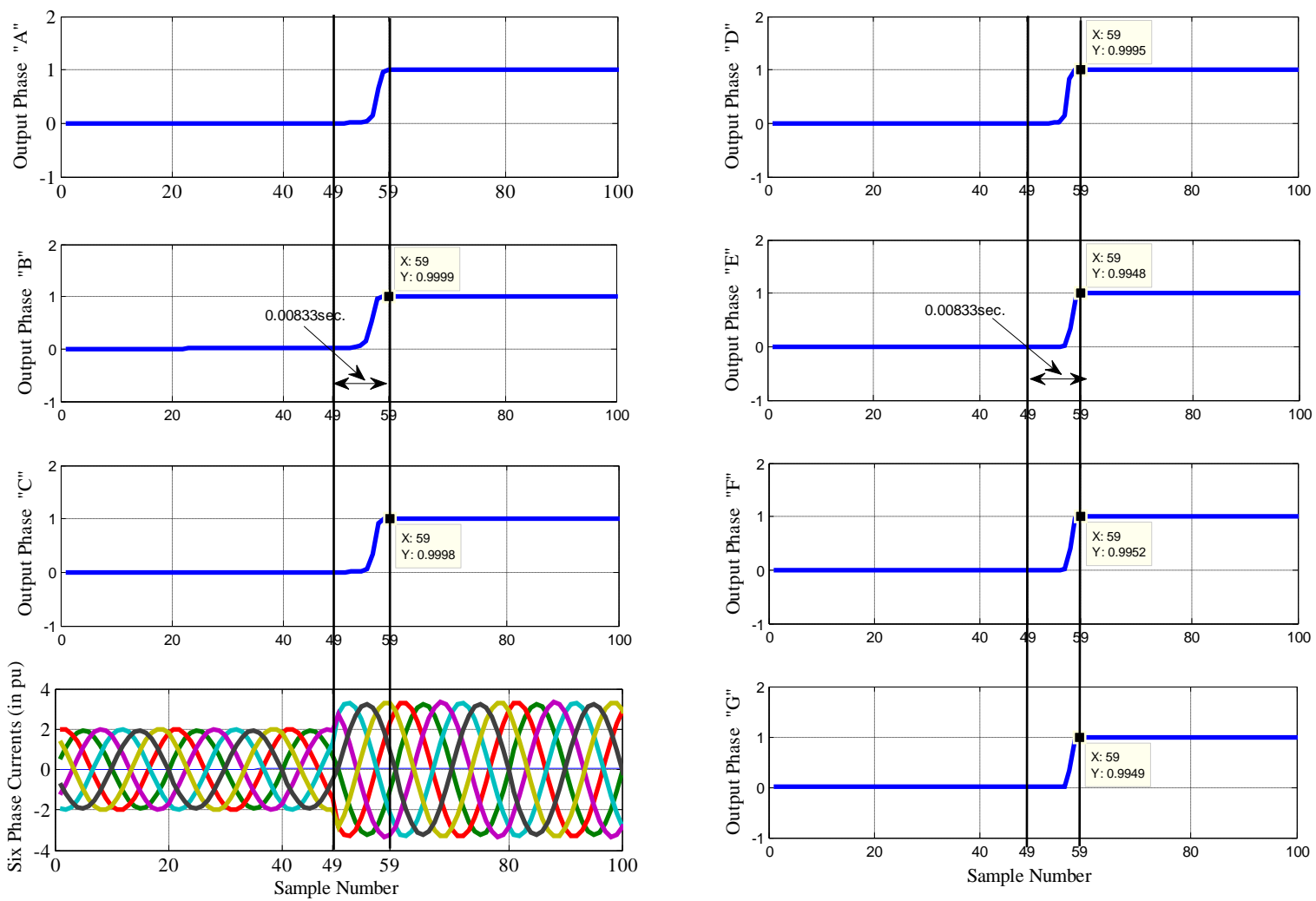

Fig.6. Test results for 6 phase to ground 'ABCDEFG' fault at $1 \mathrm{~km}$ with fault $R_{\mathrm{f}}=100 \Omega, \Phi_{\mathrm{i}}=150^{\circ}$ (fault inception time 40.8

\begin{tabular}{|c|c|c|c|c|c|}
\hline $\begin{array}{l}\text { Sample } \\
\text { No. }\end{array}$ & $\begin{array}{l}\text { Type of } \\
\text { Fault }\end{array}$ & $\begin{array}{l}\text { Fault } \\
\text { Location } \\
\text { in } \mathbf{k m} \\
\text { from the } \\
\text { relay } \\
\text { location } \\
\text { (in } \mathbf{k m} \text { ) }\end{array}$ & $\begin{array}{l}\text { Fault } \\
\text { Inception } \\
\text { Angle } \\
\left(\Phi_{\mathrm{i}} \text { in }{ }^{\circ}\right)\end{array}$ & $\begin{array}{l}\text { Fault } \\
\text { Resist } \\
\text {-ance } \\
\left(\mathbf{R}_{\mathbf{f}} \text { in }\right. \\
\mathbf{\Omega})\end{array}$ & $\begin{array}{l}\text { Phase } \\
\text { A }\end{array}$ \\
\hline $0-50$ & No Fault & - & - & - & 0 \\
\hline $51-60$ & ABCDEFG & 8 & 10 & 50 & 0.999 \\
\hline $61-70$ & ABCDEFG & 15 & 30 & 60 & 0.999 \\
\hline $71-80$ & ABCDEFG & 18 & 40 & 50 & 0.999 \\
\hline $81-90$ & ABCDEFG & 25 & 60 & 70 & 0.999 \\
\hline $91-100$ & ABCDEFG & 35 & 20 & 80 & 0.999 \\
\hline $101-110$ & ABCDEFG & 45 & 150 & 60 & 0.999 \\
\hline $111-120$ & ABCDEFG & 55 & 210 & 99 & 0.999 \\
\hline $121-130$ & ABCDEFG & 67 & 63 & 80 & 0.995 \\
\hline
\end{tabular}

This paper presents an application of ANN approach for fault detection and classification in six phase transmission lines using measured data from one terminal of the transmission line. The ANN design and implementation are aimed at highspeed processing which can provide detection and classification of faults. The ANN has been proposed not only to detect faults but also to identify the phase involved in faulted phase. The proposed technique is able to accurately identify the phase(s) involved in six phase to ground faults that may occur in a transmission line. The ANN was trained and tested using various sets of simulation data. The data are obtained from the simulation of faults at various points of a transmission line using a computer program based on Matlab. ms).

\begin{tabular}{l} 
Output of ANN based Classifier and Detector \\
\hline \begin{tabular}{l|l|l|l|l|l|}
\hline $\begin{array}{l}\text { Phase } \\
\text { B }\end{array}$ & $\begin{array}{l}\text { Phase } \\
\text { C }\end{array}$ & $\begin{array}{l}\text { Phase } \\
\text { D }\end{array}$ & $\begin{array}{l}\text { Phase } \\
\text { E }\end{array}$ & $\begin{array}{l}\text { Phase } \\
\text { F }\end{array}$ & $\begin{array}{l}\text { Ground } \\
\text { G }\end{array}$ \\
\hline 0 & 0 & 0 & 0 & 0 & 0 \\
\hline 1 & 1 & 1 & 1 & 0.999 & 0.999 \\
\hline 1 & 1 & 1 & 1 & 0.999 & 0.999 \\
\hline 1 & 1 & 1 & 1 & 0.999 & 0.999 \\
\hline 1 & 1 & 1 & 0.999 & 0.999 & 0.999 \\
\hline 1 & 1 & 1 & 0.999 & 0.999 & 0.999 \\
\hline 1 & 1 & 1 & 0.999 & 0.999 & 0.999 \\
\hline 1 & 1 & 1 & 0.999 & 0.999 & 0.999 \\
\hline 0.999 & 0.999 & 0.999 & 0.996 & 0.992 & 0.994 \\
\hline
\end{tabular}
\end{tabular}

Various fault scenarios (fault types, fault locations and fault resistance) are considered in this paper. The inputs to ANN are phase currents measured at the relay location based on fundamental components. The outputs of ANN are 1 or 0 for detection of faults and type of fault. Test results indicate that the speed and selectivity of the approach are quite robust and provide adequate performance for six phase transmission system monitoring, control and protection applications. 


\section{REFERENCES}

[1] S.N. Tiwari and G. K. Singh, "Multiphase power transmission research -a survey", Electrical Power Systems Research, 24(1992) 207-215.

[2] Navin B. Bhatt, Subrahmanyam S. Venkata, William C. Guyker and William H. Booth, "Six Phase (Multi-Phase) Power Transmission Systems: Fault Analysis", IEEE Transactions on Power Apparatus and Systems, Vol. PAS-96, No. 3 May/June 1977.

[3] J.R. Stewart, E. Kallaur, I.S. Grant, " Economics Of High Phase Order Transmission", IEEE Transaction on Power Apparatus and Systems, Vol. PAS-103, No. 11, November 1984

[4] W.C.Guyker and D.F.Shankle, "138 KV Six Phase Uprating Of A $138 \mathrm{KV}$ Double Circuit Line", IEEE Transaction on Power Apparatus and Systems, Vol. PAS-104, No. 9, September December 1985.
[5] R. Ramaswami, S. S. Venkata and M. A. El-Sharkawi, "Six-Phase Transmission Systems: Capacitance Switching", IEEE Transaction on Power Apparatus and Systems, Vol. PAS-103, No. 12, December 1984.

[6] S.S. Venkata, W.C. Guyker, J. Kondragunta, N.K. Saini and E.K. Stanek, "138-kV, SIX-PHASE TRANSMISSION SYSTEM: FAULT ANALYSIS" IEEE Transactions on Power Apparatus and Systems, Vol. PAS-101, No. 5 May 1982.

[7] M A Redfern, "Applying Distance Relays To Protect Six-Phase AC Transmission Lines" Developments in Power System Protection, 25-27th March 1997, Conference Publication No. 434, 0 IEE, 1997

[8] Vankayala, V.S., and Rao, N.D., "Artificial NNs and their application to power systems -a bibliographical survey", International Journal of Electrical Power System Research, 28, 1993, pp. 67-79. 